\title{
Gastric ulcer and the anti-arthritic drugs
}

\author{
J. H. EmmanueL* \\ M.B., Ch.B.
}

R. D. MONTGOMERY

M.D., F.R.C.P.Ed., M.R.C.P.

\section{The Gastrointestinal Unit. East Birmingham Hospital, Birmingham, 9}

\section{Summary}

Sixteen cases are described of gastric ulcer in patients receiving anti-arthritic drugs. Half of the ulcers were in the antrum or on the greater curve. Ten patients were under treatment with indomethacin and/or prednisone, seven of them receiving both drugs.

The ulcers healed readily when the drugs were withdrawn, and in the case of prednisone a continued daily dose of $10 \mathrm{mg}$ or less did not prevent healing.

All the patients with haemorrhage were taking aspirin, with or without other drugs.

The literature is reviewed, and it is suggested that the increased incidence of peptic ulcer in patients receiving anti-arthritic drugs is confined to gastric ulcer. There is suggestive evidence of an increased susceptibility to antral ulcer in severe rheumatoid disease, which may largely account for the 'steroid ulcer'.

Indomethacin is potentially ulcerogenic, and its combined use with steroids may be inadvisable. Apart from its tendency to produce haemorrhagic erosions, the role of aspirin in the aetiology of chronic ulcer remains doubtful. No serious ill-effects have been reported in the use of ibuprofen or Distalgesic in ulcer subjects.

INDOMETHACIN is well known to produce gastrointestinal side-effects, and recent reports have suggested that it may induce chronic gastric ulceration, often with a tendency to haemorrhage (Lovgren \& Allander, 1964; Taylor et al., 1968). It has been believed for many years that steroid therapy may induce peptic ulceration, at least in rheumatoid patients, and phenylbutazone and oxyphenbutazone are also said to be a cause of gastric ulcer and haemorrhage. With all these drugs the ulcers tend to occur at unusual sites, especially in the antrum. Finally, aspirin which is known to induce gastric bleeding has recently been incriminated in the aetiology of chronic gastric ulcer in women (Chapman \& Duggan, 1969).

Many arthritic patients require multiple drugs to

* Present addrcss King's College Hospital, Denmark Hill, London, S.E.5. control their symptoms, and when a gastric ulcer supervenes the problem of therapy can be a serious one, particularly as the relative risks of the various drugs are still not understood.

\section{Clinical features}

We report our experience with sixteen arthritic patients suffering from gastric ulcer. Five were male and eleven female. Their age ranged from 43 to 80 years with an average of 64 years. Ten suffered from rheumatoid disease (one with psoriasis) and six had degenerative arthritis. Other data are given in Table 1.

Three patients, all with ulcers on the lesser curve, had a past history suggesting that an ulcer may have been present before the administration of antiarthritic drugs. The site of ulceration in the remaining thirteen cases is shown in Table 2 and compared with the distribution in a control series of 122 non-arthritic cases of gastric ulcer diagnosed during the same period. There is a strong predilection for the posterior wall and greater curve of the antrum, and to a lesser extent of the fundus.

Ten of these thirteen patients were receiving indomethacin and/or steroid drugs. Case 2 had indomethacin alone. Case 4 had taken prednisone (7.5-10 mg daily) for 6 years without ill-effect, and epigastric pains only began 1 month after indomethacin was added. The ulcer healed when indomethacin was stopped but prednisone was continued. In Case 9 epigastric pains began when she was receiving indomethacin alone, although perforation and haemorrhage followed the addition of steroids. Cases 3, 5 and 6 developed acute symptoms while on both drugs but in all three cases the ulcer healed when indomethacin was stopped and steroids were continued.

Cases 10 and 12, both with ulcers on the posterior wall of the antrum, developed symptoms while on regular doses of $10-15 \mathrm{mg}$ of prednisone. This was withdrawn in Case 10 and continued (7.5 mg daily) in Case 12, and both ulcers healed.

All of the nine cases receiving prednisone had rheumatoid arthritis. To view these figures from 
TABLE 1. Features of gastric ulcer in sixteen patients receiving anti-arthritic drugs

\begin{tabular}{|c|c|c|c|c|c|c|c|c|c|}
\hline \multirow{2}{*}{ Case No. } & \multirow{2}{*}{ Sex } & \multirow{2}{*}{ Disease } & \multirow{2}{*}{ Ulcer site } & \multirow{2}{*}{ Haemorrhage } & \multirow{2}{*}{ Perforation } & \multicolumn{4}{|c|}{ Drugs } \\
\hline & & & & & & Im & Pred & PB & Sal \\
\hline $1 *$ & $\mathbf{M}$ & OA & High lesser curve & - & - & + & & & \\
\hline 2 & $\mathbf{F}$ & $\mathbf{O A}$ & Mid lesser curve & - & - & + & & & \\
\hline 3 & $\mathbf{F}$ & $\mathbf{R h}$ & Mid lesser curve & - & - & + & + & & \\
\hline 4 & $\mathrm{~F}$ & $\mathbf{R h}$ & Post. antrum & - & - & + & + & & \\
\hline 5 & $\mathbf{F}$ & $\mathbf{R h}$ & Post. antrum & - & + & + & + & & \\
\hline 6 & $\mathbf{M}$ & $\mathbf{R h}$ & High post. fundus & - & - & + & + & + & \\
\hline $7^{*}$ & $\mathbf{M}$ & $\mathbf{O A}$ & Mid lesser curve & - & - & + & & + & $+\stackrel{0}{\omega}$ \\
\hline 8 & $\mathbf{F}$ & $\mathbf{R h}$ & Greater curve fundus & ++ & - & + & + & & + \\
\hline 9 & $\mathbf{F}$ & $\mathbf{R h}$ & Greater curve antrum & ++ & + & + & + & & + \\
\hline 10 & $\mathbf{F}$ & $\mathbf{R h}$ & Post. antrum & - & - & & + & & +7 \\
\hline $11^{*}$ & $\mathbf{M}$ & $\mathbf{R h}$ & Mid lesser curve & - & - & & + & & + \\
\hline 12 & $\mathbf{F}$ & $\mathbf{R h}$ & Post. antrum & 一 & - & & + & + & \\
\hline 13 & $\mathbf{M}$ & OA & High lesser curve & + & - & & & + & 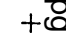 \\
\hline 14 & $\mathbf{F}$ & OA & Lesser curve antrum & + & - & & & & \\
\hline 15 & $\mathbf{F}$ & $\mathbf{O A}$ & High post. fundus & - & - & & & & + \\
\hline 16 & $\mathbf{F}$ & $\mathbf{R h}$ & Mid lesser curve & ++ & - & & & & + \\
\hline
\end{tabular}

TABLE 2. Site of ulceration in thirteen cases whose symptoms commenced during therapy: comparison with 122 nonarthritic cases

\begin{tabular}{lcc}
\hline & \multicolumn{2}{c}{ Distribution (\%) } \\
\cline { 2 - 3 } Site & Arthritic cases & Non-arthritic cases \\
\hline $\begin{array}{l}\text { Antrum: } \\
\text { Lesser curve } \\
\begin{array}{l}\text { Posterior wall and } \\
\text { greater curve }\end{array}\end{array}$ & 8 & 8 \\
$\begin{array}{l}\text { Corpus: } \\
\text { Lesser curve } \\
\text { Posterior wall and } \\
\text { greater curve }\end{array}$ & 31 & 3 \\
\hline
\end{tabular}

another aspect, of twenty consecutive cases of benign ulceration of the antrum seen in a gastrointestinal clinic, one-quarter were under treatment for severe rheumatoid disease.

\section{Complications}

Cases of haemorrhage and perforation are recorded in Table 1. It is noteworthy that all of the five patients with gastric haemorrhage were taking salicylates at the time. In Case 9 an emergency gastrectomy was performed for continuing haemorrhage and a deep ulcer with local perforation was found on the greater curve of the antrum. Histology showed an unusual degree of surrounding necrosis. The patient had taken indomethacin regularly for 2 years with intermittent aspirin, and had also had Medrone Medules $12 \mathrm{mg}$ daily for 3 weeks. Epigastric pains had been present for 6 months. Case 8 was a woman aged 79 who had a massive and fatal haemorrhage while taking prednisone $15 \mathrm{mg}$ daily, indomethacin $300 \mathrm{mg}$ daily and numerous tablets of aspirin, phenacetin and codeine. Necropsy revealed $\stackrel{\text { 을 }}{-}$ a large ulcer on the greater curve of the fundus of $>$ the stomach. Histology showed extensive necrosis? but confirmed the benign nature of the lesion. In $\overrightarrow{\vec{\theta}}$ Case 5, following an episode of intense continuous pains, there was radiological evidence of a localized. perforation of an ulcer in the posterior wall of the antrum. The patient was on regular doses of both indomethacin and prednisone. The former waso discontinued, the latter was reduced from 12.5 too $7.5 \mathrm{mg}$ daily, and the ulcer healed without surgery.

\section{Further management}

With the exception of Case 8 who died and Case 9 ? who was treated surgically, all the remaining cases? showed healing of their ulcers within a few months.을 Medical management included the administration of carbenoxolone sodium in four cases. Indomethacin, $\frac{}{3}$ salicylates and phenylbutazone were withdrawn in the relevant cases, but as already mentioned predni-윽 sone therapy was continued in five of the nine cases who were receiving it, and this did not prevent? symptomatic relief and radiological healing. The $\frac{7}{2}$ highest dose which was continued in these cases was $10 \mathrm{mg}$ daily.

Several patients suffered from exacerbation of their arthritic pains on withdrawal of drugs. In these cases paracetamol was the mainstay of treatment, $\omega$ sometimes prescribed as compound tablets with dextropropoxyphene (Distalgesic). Several patientso received ibuprofen with moderate success and with no dyspeptic complications. Two cases were treated with mefenamic acid but in one of them this was abandoned because of intractable diarrhoea and a relapse of dyspepsia. 


\section{Discussion}

\section{Gastric ulcer in rheumatoid disease}

The effects of drugs on the stomach in arthritic patients must be considered against the background of the incidence of gastric ulcer, firstly in the general population of comparable age and sex distribution, and secondly in comparable patients suffering from arthritis, particularly rheumatoid disease. With regard to salicylates, it seems impossible to separate the effects of treatment from the effects of rheumatoid disease, since nearly all arthritic sufferers at some time or other take salicylate drugs, whether or not these have been prescribed. In the case of other drugs which have been progressively introduced one can compare the incidence of ulceration with 'controls' before the introduction of the drug. Here however discrepancies may arise because of a changing incidence of ulcer in the population, changing criteria of diagnosis, and the fact that the drugs may alter the manner in which the ulcer presents. Comparability of the 'incidence' in control groups will also depend upon the period of observation during which the occurrence of fresh ulceration was considered. Even if an ideal control group can be studied over a comparable length of time, there is a possibility of bias in the diagnosis of doubtful cases.

Hence it is not surprising that there are wide differences in the reported incidence of peptic ulcer in rheumatoid disease. The evidence has been carefully reviewed by Spiro \& Milles (1960) and Crean (1963).

The overall incidence of peptic ulcer in Britain has been estimated at about $8 \%$ occurring at some time during life (Doll, Jones \& Buckatzsch, 1951), but figures based purely on necropsy findings are higher (Watkinson, 1960). The prevalence of active ulcer at any one time, or the incidence during any single period of a year will obviously be consideratly lower, but no accurate figures are available. The incidence of activity of gastric ulcers is higher in the second half of life, when arthritis is common.

With regard to rheumatoid patients, the incidence of peptic ulcer has been variously estimated at between 5 and $8 \%$ (Ragan, 1951; Short, Bower \& Reynolds, 1957; Baragar \& Duthie, 1960; Bowen et al., 1960; Gibberd, 1966). As already mentioned, the estimates include rather variable criteria, and variable periods of observation. The possible role of salicylates cannot be excluded, and none of these series provides adequate data as to changes in the incidence of gastric relative to duodenal ulcer. Overall, the figures do not suggest any significant increase in peptic ulceration due to the rheumatoid process. Conversely they could conceal a minor increase in susceptibility to ulceration at certain sites. This is not impossible in view of the generalized abnormalities of tissue reactivity which can be demonstrated in rheumatoid disease.

\section{Corticosteroids}

The relationship of steroid therapy to peptic ulcer is a complex problem. Whereas Sinclair (1965) stated that the evidence was overhwelming that cortisol and its analogues produced peptic ulceration, according to Croft (1969) 'there is no evidence that corticosteroids in the usual doses cause gastric bleeding or are otherwise harmful to the human stomach'. This problem has also been considered by Spiro \& Milles (1960), Crean (1963) and Cooke (1967).

Discrepancies in the literature stem from the fact that a high incidence of peptic ulceration has chiefly been reported in cases of rheumatoid disease, and chiefly in those receiving a higher dose-range of steroids. Bearing in mind all the variables mentioned earlier, one must still consider the massive evidence of correlation between peptic ulcer and steroid therapy (Kern, Clark \& Lubens, 1957; Black, Yielding \& Bunlin, 1958; Howell \& Ragan, 1956; Edgecomb, 1958; Kammerer, Frieberger \& Rivelis, 1958; Evans, 1958; Gedda \& Moritz, 1959). The incidence of peptic ulcer in these series ranged from 12.5 to $31 \%$. Consistent features of the ulcers were that they occurred with approximately equal frequency in men and women, the presentation was sometimes silent with serious complications, and there was a marked predominance of gastric rather than duodenal ulceration, particularly in the gastric antrum. This unusual distribution of the site of ulceration is the most convincing evidence of a direct association between steroid therapy and the ulcer. It is well illustrated by the prospective studies of Kammerer et al. (1958) and Gedda \& Moritz (1959). In their combined series, forty-one out of forty-nine ulcers were gastric, and this accentuates the difference as compared with the incidence in their controls examined by radiology or at autopsy. Whereas Bowen et al. (1960) found no obvious effect of steroids on the overall figures for peptic ulcer in rheumatoid patients at the Mayo Clinic, they nevertheless were able to demonstrate a marked increase in the incidence of gastric ulcer.

The risk of ulceration seems to be dose-related, and the borderline level of prednisone therapy is of the order of $15 \mathrm{mg}$ daily. In reported series of rheumatoid patients with negative or equivocal findings of peptic ulceration the daily dose has been less than $20 \mathrm{mg}$ daily (Meltzer et al., 1958; Mongan et al., 1964). On the other hand in the series of Gedda \& Moritz (1959) twelve out of thirteen patients had received less than $15 \mathrm{mg}$ daily.

In considering the evidence, there are two caveats. Firstly there is the possibility of bias in radiological 
diagnosis. A bias in favour of diagnosing gastric ulcer might tend to affect both sexes equally, and it might tend to increase the incidence of antral ulceration, since difficulties of interpretation arise in the antrum rather than on the lesser curve. (In our series the association with arthritis was sought retrospectively, and there should be no bias in the original diagnosis.)

Secondly as Crean (1963) pointed out, ste oid therapy tends to be given to the more severe cases of rheumatoid disease; and none of the published evidence excludes the possibility that an increase in peptic ulcer, particularly of the gastric antrum, is a feature of severe rheumatoid disease rather than of steroid therapy.

These views are not incompatible. In rheumatoid disease there may be a diminished resistance to a whole variety of agents which tend to induce gastric erosions. The healing of such erosions may be hindered by additional steroid therapy. There is good evidence that the healing of experimental ulceration is delayed (but not prevented) by steroid treatment, with inhibition of fibroplasia (Janowitz et al., 1958; Kahn, Phillips \& Skoryna, 1961). Although prolonged steroid therapy may give rise in some individuals to an increase in gastric acid secretion (Gray et al., 1953; Crean, 1960), most of the literature on 'steroid ulcer' stresses that a reduction of mucosal resistance is the main factor. Hirschowitz et al. (1955) and Kammerer et al. (1958) recorded a decrease in the viscosity of gastric juice and the former reported a reduction in stainable mucus on the gastric surface.

For these reasons one would expect a combination of steroids and other ulcerogenic drugs to be particularly dangerous. Gastric erosions due to salicylates commonly occur in the antrum and lesser curve (Muir \& Cossar, 1955; Croft \& Wood, 1967); and it was suggested by Spiro \& Milles (1960) that steroids might prevent the repair of such erosions. This is a possibility, although one might expect in these circumstances that multiple ulcers would be common. Moreover the well-recognized tendency to bleeding brought about by salicylates is not a feature of 'steroid ulcers' (Scott et al., 1961)

In view of all the possible discrepancies in estimating ulcer incidence, it is perhaps surprising that (apart from a few reports in the early days of steroid therapy) it is now generally agreed that steroids do not increase the tendency to ulcer in conditions other than rheumatoid disease. An ulcer incidence of the order of $2 \%$ over variable periods has been found in cases of asthma (Rees \& Williams, 1962), ulcerative colitis (Truelove \& Witts, 1955; Palmer \& Kirsner, 1959) and chronic skin disease (Spiro \& Milles, 1960).

In summary, it becomes clear that in patients with severe rheumatoid disease treated with steroids there is an increased incidence of gastric ulcer. Thiso increase applies particularly, and perhaps exclu- $\frac{0}{c}$ sively, to the gastric antrum. Uncertainty remains as. to whether this is due to severe rheumatoid diseases? itself, to steroid therapy, to concomitant aspirino therapy, or to a combination of all these factors.

\section{Indomethacin}

Although much less has been written about theon gastrointestinal effects of indomethacin, the subjects is less controversial. In addition to a high incidence of dyspepsia there is no doubt that in a much smaller $\vec{\omega}$ number of cases fresh peptic ulceration can occur, $\stackrel{\omega}{\sigma}$ with a strong tendency to healing when the drug is? withdrawn. Taylor et al. (1968) described a series of 3 . cases in which no other anti-arthritic drugs had been:given. Ulcers attributed to indomethacin tend toor occur in similar sites to those occurring in patients receiving steroid therapy. In the case of indo- N methacin, no evidence has been offered that the $v$ incidence of side-effects is dose-related. Nor is을 there any detailed evidence of the mode of action ongastrointestinal mucosa. Intestinal ulceration has been demonstrated in experimental animals, with a marked species specificity, and can be induced when $\overrightarrow{0}$ the drug is injected. Taylor et al. (1968) describegd three cases of gastric ulcer in patients who we receiving indomethacin by suppository only. Tes tendency to occult bleeding seems to be less than that associated with aspirin (Wanka et al., 1964).

We have described nine cases of gastric ulcer in patients receiving indomethacin, and the histories strongly suggest a causal relationship in at least seveno을 of them. Six of these were also receiving prednisone and it is likely that the two drugs acted synergistically. It is significant that healing was observed while a number of patients continued prednisone in reduced dose.

\section{Phenylbutazone and oxyphenbutazone}

The incidence of dyspepsia in patients receiving these drugs was put as high as $20 \%$ in earlier reports (Nassim \& Pilkington, 1953; Mason \& Hayter, 1958), but long-term therapy in a lower dose range gave rise to mild dyspepsia in only $4 \%$ of 562 . patients (Sperling, 1969). A tendency to erosive $N$ gastritis and haemorrhage is well established (Hartr \& Johnson, 1952; Scott et al., 1961; Roth, 1964). N The actual incidence of chronic peptic ulceration $\sigma$ arising during therapy is not clear but probably very low (Sperling, 1969; Croft, 1969). Among the smalf numbers reported, however, there has been a preponderance of cases in the stomach rather than the duodenum, and the sex-incidence is approximately equal. Multiple gastric ulcers have been described $\overrightarrow{\mathbb{D}}$ (British Medical Journal, 1952; Raffensperger, 
1953). The action of these drugs is at least partly systemic, as shown by animal experiments and by a high incidence of dyspepsia when the drugs are given by injection (Davis, 1952).

\section{Salicylates}

In the enormous literature on the effects of salicylates on the gastrointestinal tract, no positive evidence has emerged that the incidence of chronic peptic ulcer is increased by these drugs. As in the case of phenylbutazone and oxyphenbutazone, a tendency to erosive gastritis and gastro-duodenal haemorrhage is demonstrable, and salicylates also enhance the bleeding tendency of established chronic ulcers (Muir \& Cossar, 1959; Scott et al., 1961 ; Roth, 1964; Croft \& Wood, 1967; Valman, Parry \& Coghill, 1968). The mucosal damage is greatest with direct contact, but is still apparent after parenteral administration. Menguy \& Masters (1965) observed a reduction and altered composition of gastric mucus in animals given aspirin parenterally, the effect being similar to that of cortisone. There may be less occult blood loss with the use of aloxiprin than other forms, but soluble and buffered aspirin have no demonstrable advantage in this respect (Wood, Harvey-Smith \& Dixon, 1962), and all aspirin derivatives are liable to exacerbate dyspepsia in ulcer subjects.

This question has been reactivated by the statistical evidence offered from New South Wales on the relation of gastric ulcers in women to the ingestion of aspirin-containing preparations (Douglas \& Johnston, 1961; Chapman \& Duggan, 1969; Gillies \& Skyring, 1969). At present these studies can only be viewed against the background of failure to demonstrate an increase in the incidence of chronic ulcers in patients receiving long-term salicylate therapy for rheumatoid disease (Baragar \& Duthie, 1960; Gibberd, 1966). Although the possibilities of such a special relationship have already been discussed, they remain hypothetical.

\section{Other analgesics}

Mefenamic acid, which has useful analgesic and anti-inflammatory action in musculo-skeletal disorders, has been shown to induce gastro-intestinal erosions in animals. Occasional dyspeptic symptoms and a rather high incidence of diarrhoea accompany its use in man (Bissell, 1965; Myles, Bacon \& Williams, 1967). Although in most patients these side-effects are not incapacitating, the drug is obviously a poor alternative to salicylates and indomethacin in patients with peptic ulcer. Ibuprofen is more promising in this respect. Our experience confirms that of Cardoe (1969) that gastric tolerance is good, even in ulcer subjects. Although the drug is a weak analgesic and is not superior to aspirin, it has been used successfully in patients who exhibited dyspepsia with aspirin (Chalmers, 1969). It may prove to be the best alternative drug in ulcer patients with arthritis.

Finally, compound tablets of dextropropoxyphene and paracetamol (Distalgesic) provide a combination of two mild analgesics; no specific anti-inflammatory action can be claimed for them, but they have the advantage that the dosage can be built up to relatively high levels with very little risk of gastrointestinal side-effects (Gruber, 1957; British Medical Journal, 1963).

\section{References}

BARAgaR, F.F. \& Duthie, J.J.R. (1969) Importance of aspirin as a cause of anaemia and peptic ulcer in rheumatoid arthritis. British Medical Journal, 1, 1106.

Bissell, S.W. (1965) A trial of a new analgesic in general practice. Practitioner, 194, 817.

BlaCK, R.K., Yielding, K.L. \& Bunlin, J.J. (1958) Observations on new synthetic antirheumatic steroids and critical evaluation of prednisone therapy in rheumatoid arthritis. Journal of Chronic Diseases, 5, 751.

Bowen, R. Jr, Mayne, J.G., Cain, J.C. \& Bartholemew, L.G. (1960) Peptic ulcer in rheumatoid arthritis and relationship to steroid treatment. Proceedings of the Mayo Clinic, 35, 537.

British Medical Journal (1952) Deaths due to butazolidin. British Medical Journal, 2, 1427.

British Medical Journal (1963) Today's drugs: mild analgesics. British Medical Journal, 1, 317.

CARDOE, N. (1969) Ibuprofen in the treatment of rheumatoid disease and osteoarthritis of the hip. Paper read at the 12 th International Congress of Rheumatology, Prague.

Chalmers, T.M. (1969) Clinical experience with ibuprofen in the treatment of rheumatoid arthritis. Annals of Rheumatic Diseases, 28, 513.

Chapman, B.L. \& Duggan, J.M. (1969) Aspirin and uncomplicated gastric ulcer. Gut, 10, 443.

Cooke, A.R. (1967) Corticosteroids and peptic ulcer: is there a relationship? American Journal of Digestive Diseases, 12, 323.

Crean, G.P. (1960) The effects of A.C.T.H. and corticosteroids on gastric secretion in humans. Gut, $1,82$.

Croft, D.N. (1969) Gastric bleeding due to drugs. Prescribers Journal, 10, 14.

Croft, D.N. \& Wood, P.H.M. (1967) Gastric mucosa and susceptibility to occult gastrointestinal bleeding caused by aspirin. British Medical Journal, 1, 137.

Davies, R.H.H., BARTER, R.W. \& Gee, A. (1952) Observations on the use of 'butazolidin' in arthritis. British Medical Journal, 2, 1392.

Doll, R., Jones, F.A. \& Buckatzsch, M.M. (1951) Occupational factors in the aetiology of gastric and duodenal ulcers, with an estimate of their incidence in the general population. Medical Research Council Special Report Series, No. 276. H.M.S.O., London.

Douglas, R.A. \& Johnston, E.D. (1961). Aspirin and chronic gastric ulcer. Medical Journal of Australia, 2, 893.

EDGECOMB, J.H. (1958) On development of peptic ulcers in patients treated with prednisone or prednisolone. Schweizerische Zeitschrift für Pathologie und Bakteriologie, 21, 363.

Evans, K.T. (1958). Peptic ulcer associated with prednisolone therapy. British Journal of Radiology, 31, 307.

Gedda, P.O. \& Moritz, V. (1959) Peptic ulcer during treatment of rheumatoid arthritis with cortisone deriva- 
tives: relationship between duration of therapy and frequency of ulcers. Acta rheumatologica scandinavica, 4, 249.

GibBerd, F.B. (1966) Dyspepsia in patients with rheumatoid arthritis. Acta rheumatologica scandinavica, 12, 112.

Gillies, M.A. \& Skyring, A. (1969) Aspirin, smoking, family history in gastric ulcers. Medical Journal of Australia, 2, 280.

Gray, S.J., Ramsey, C.G., Reifenstein, R.W. \& Benson, R.A. Jr (1953) Significance of hormonal factors in pathogenesis of peptic ulcer. Gastroenterology, 25, 156.

GruBER, C.M. (1957) Codeine phosphate, propoxyphene hydrochloride, and placebo. Journal of the American Medical Association, 164, 966.

HART, F.D. \& JohnSON, A.M. (1952) Butazolidin. Lancet, ii, 587.

Hirschowitz, B.I., Streeten, D.H.P., Pollard, H.M. \& BoldT, H.A. Jr (1955) Role of gastric secretions in activation of peptic ulcers by corticotropin (ACTH). Journal of the American Medical Association, 158, 27.

Howell, D.S. \& RAGAN, C. (1956) Course of rheumatoid arthritis during four years of induced hyperadrenalism (IHA). Medicine, 35, 83.

Janowitz, H.D., Weinstein, J.A., Shaer, R.G., Cereghini, J.F. \& Hollander, F. (1958) Effect of cortisone and corticotropin on healing of gastric ulcer: experimental study. Gastroenterology, 34, 11.

Kahn, D.S., Phillips, M.J. \& Skoryna, S.S. (1961) The early penetration of experimental gastric ulcers in rats receiving cortisone. American Journal of Pathology, 38, 73. Healed experimental gastric ulcer in the rat; re-ulceration resulting from cortisone administration. American Journal of Pathology, 38, 177.

Kammerer, W.H., Frieberger, R.H. \& Rivelis, A.L. (1958) Peptic ulcer in rheumatoid patients on corticosteroid therapy: clinical, experimental and radiologic studv. Arthritis and Rheumatism, 1, 122.

Kern, F., Jr, Clark, G.M. \& Lukens, J.G. (1957) Peptic ulceration occurring during therapy for rheumatoid arthritis. Gastroenterology, 33, 25.

Lovgren, O. \& Allander, E. (1964) Side-effects of indomethacin. British Medical Journal, 1, 118.

MASON, R.M. \& HAYTER, R.R.P. (1958) The present status of phenylbutazone therapy in rheumatic disease. Practitioner, $181,23$.

Meltzer, L.E., Bockman, A.A., Kanenson, W. \& Cohen, A. (1958) Incidence of peptic ulcer among patients on longterm prednisone therapy. Gastroenterology, 35, 351 .

MenguY, R. \& MASTERS, Y.F. (1965) Effects of aspirin on gastric mucus secretion. Surgery, Gynecology and Obstetrics, 120, 92.

Mongan, E.S., Atwater, E.C., Jacox, R.F. \& Wieche, D.R. (1964) A prospective study of peptic ulcer in patients with rheumatoid arthritis. Annals of Internal Medicine, 60, 740.
Muir, A. \& Cossar, I.A. (1955) Aspirin and ulcer. Britis Medical Journal, $2,7$.

Myles, A.B., Bacon, P.A. \& Williams, K.A. (1967) Mefen amic acid in rheumatoid arthritis. Annals of Rheumatic Diseases, 26, 494.

Nassim, J.R. \& Pilkington, T. (1953) Toxic effects of phenyl butazone. British Medical Journal, 1, 1310.

Palmer, W.L. \& Kirsner, J.B. (1959) Therapeutic and side effects of the anti-inflammatory steroids on the gastro음 intestinal tract. Annals of the New York Academy of Sciences, 82, 947.

RAFFENSPERGER, E.C. (1953) Multiple gastric ulcers occurring during phenylbutazone therapy. Journal of the Americans Medical Association, 152, 30.

RaGan, C. (1951) In: Connective Tissue, Transactions of the $\vec{\circ}$ 4 th Conference, p. 137. Josiah Micy Foundation, New York.

ReEs, H. A. \& Williams, D.A. (1962) Long-term steroiक therapy in chronic intractable asthma. British Medica Journal, 1, 1575.

Roth, J.L.A. (1964) Role of drugs in production of gastro is duodenal ulcer. Journal of the American Medical Association, $187,419$.

Scott, J.T., Porter, I.H., Lewis, S.M. \& Dixon, A. St.J⿳亠丷厂 (1961) Studies of gastrointestinal bleeding caused by corticosteroids, salicylates, and other analgesics. Quarterly Journal of Medicine, 30, 167.

SHORT, C.L., BOWER, W. \& REYNolds, W.E. (1957) In? Rheumatoid Arthritis, p. 188. Harvard University Press Cambridge, Massachusetts.

SinclaIR, R.J.G. (1965) In: Progress in Clinical Rheuma tology (Ed. by A. St.J. Dixon). Churchill, London.

SPERLING, I.L. (1969) Adverse reactions with long-term us 80 phenylbutazone and oxyphenbutazone. Lancet, ii, 535. -

SPIRO, A.M. \& Milles, S.S. (1960) Clinical physiologic mim plications of the steroid-induced peptic ulcer. New Eng Journal of Medicine, 263, 286.

TAYlOR, R.T., HuskisSON, E.C., Whitehouse, G.H. \& HART, F.D. (1968) Gastric ulceration during indomethaciff therapy. British Medical Journaf, 4, 734.

Truelove, S.C. \& WITts, L.J. (1955) Cortisone in ulcerative colitis: final report on therapeutic trial. British Medica $\bar{b}$ Journal, 2, 1041.

Valman, H.B., Parry, D.J. \& Coghill, N.F. (1968) Lesions associated with gastroduodenal haemorrhage in relation to aspirin intake. British Medical Journal, 4, 661.

W ANKa, J., Jones, L.I., Wood, P.N.H. \& Dixon, A.ST.J은 (1964) Indomethacin in rheumatic diseases. Annals of Rheumatic Diseases, 23, 218.

IVATKINSON, G. (1960) The incidence of chronic peptic ulcee found at necropsy. Gut, 1, 14.

Wood, P.H.N., Harvey-Smith, E.A \& Dixon, A. St.J. (1962) Salicylates and gastrointestinal bleeding. British Medical Journal, 1, 669. 